\title{
Análise de uma intervenção dirigida ao desenvolvimento da coordenaçáo motora fina, global e do equilíbrio
}

\author{
Letícia Carrillo Maronesi ${ }^{a}$, Mirela de Oliveira Figueiredo ${ }^{b}$, Elisandra dos Santos ${ }^{c, d}$, \\ Sheila Maria Mazer-Gonçalves ${ }^{\mathrm{e}}$, Sara Domiciano Franco Campos ${ }^{\mathrm{f}}$ \\ aAssociação de Amigos dos Excepcionais, Limeira, SP, Brasil. \\ ${ }^{b}$ Departamento de Terapia Ocupacional, Universidade Federal de São Carlos - UFSCar, São Carlos, SP, Brasil. \\ 'Prefeitura Municipal de Américo Brasiliense, Américo Brasiliense, SP, Brasil. \\ ${ }^{d}$ Faculdade de Educação São Luís - FESL, Jaboticabal, SP, Brasil. \\ ${ }^{\mathrm{e}}$ Faculdade de Filosofia Ciências e Letras de Ribeirão Preto, \\ Universidade de São Paulo, Ribeirão Preto, SP, Brasil. \\ ${ }^{\mathrm{f} A s s o c i a c ̧ a ̃ o ~ d e ~ R e a b i l i t a c ̧ a ̃ o ~ I n f a n t i l ~ L i m e i r e n s e, ~ L i m e i r a, ~ S P, ~ B r a s i l . ~}$
}

\begin{abstract}
Resumo: Introdução: As aquisições motoras das crianças evoluem de acordo com a idade e com a influência contínua de fatores intrínsecos e extrínsecos, os quais provocam variações de uma criança para outra e tornam único o curso do desenvolvimento. Objetivo: Elaborar uma intervenção para uma criança com atraso na coordenação motora fina, global e no equilíbrio e analisar o impacto no desenvolvimento. Método: Design quase-experimental do tipo pré e pós-teste. O instrumento utilizado foi a Escala de Desenvolvimento Motor aplicada em uma criança de 4 anos. A partir dos resultados obtidos na avaliação foi elaborado um plano de intervenção composto por atividades dirigidas que estimulassem as aquisições acima citadas. A concretização do plano de intervenção teve duração de 2 meses, sendo a criança avaliada antes e ao término da intervenção para verificar se houve ganho nas aquisições estimuladas. O Método JT foi adotado para análise dos dados e verificação de ocorrência de mudanças positivas confiáveis e clinicamente relevantes. Resultados: Os resultados obtidos no presente estudo demonstram que ocorreram mudanças positivas confiáveis nos itens psicomotores que passaram por estimulação. Conclusão: Infere-se que a intervenção proposta teve um efeito positivo sobre o desenvolvimento da criança. Com isso, o estudo contribui para melhoria no cuidado oferecido a crianças com atrasos no desenvolvimento psicomotor, ilustrando possibilidades de estratégias e atividades. Também possibilita o reconhecimento da ação do terapeuta ocupacional como um dos profissionais que compõe a equipe multidisciplinar voltada à intervenção precoce.
\end{abstract}

Palavras-chave: Coordenação Motora Fina, Coordenação Motora Global, Equilíbrio, Intervenção, Terapia Ocupacional.

\section{Analysis of an intervention directed to the development of balance and gross and fine motor coordination}

\begin{abstract}
Introduction: Children's motor skills evolve according to age and the continuing influence of intrinsic and extrinsic factors that cause variations from one child to another; this makes the course of development unique in each child. Objective: To develop an intervention for a child with delays in fine motor coordination, gross motor coordination and balance and analyze its impact on the child's development. Methods: Pre- and post-test
\end{abstract}

Autor para Correspondência: Mirela de Oliveira Figueiredo, Laboratório de Atividade e Desenvolvimento, Departamento de Terapia Ocupacional, Universidade Federal de São Carlos, Rodovia Washington Luís, Km 235, s/n, Jardim Guanabara, São Carlos, SP, Brasil, e-mail: mirelafigueiredo@hotmail.com

Recebido em Maio 24, 2014; $1^{\text {a }}$ Revisão em Jul. 25, 2014; $2^{\text {a }}$ Revisão em Nov. 26, 2014; Aceito em Fev. 6, 2015. 
quasi-experimental design. The instrument used was the Motor Development Scale applied to a 4 year old child. An intervention plan was developed based on the results obtained throught the tests. The plan consists of activities designed to stimulate the aforementioned acquisitions. The implementation of the intervention plan lasted two months. The child was tested at the beginning and at the end of the intervention to determine whether there was gain in the stimulated acquisitions. The JT method was adopted for data analysis and verification of occurrence of reliable and clinically relevant positive changes. Results: The results of this study demonstrate that reliable positive changes occurred with respect to the psychomotor items that underwent stimulation. Conclusion: It is possible to infer that this intervention had a positive effect on the child's development. Hence, this study contributes to improve the care provided to children with delayed psychomotor development, illustrating possibilities of strategies and activities. It also allows the recognition of the action of occupational therapists as one of the professionals who compose the multidisciplinary team focused on early intervention.

Keywords: Fine Motor Coordination, Gross Motor Coordination, Balance, Intervention, Occupational Therapy.

\section{Introdução}

Desde o momento da concepção, o organismo humano tem uma organização biológica, um calendário maturativo e evolutivo, uma porta aberta à integração e à estimulação. As possibilidades motoras da criança evoluem amplamente de acordo com sua idade e chegam a ser cada vez mais variadas, completas e complexas (ROSA NETO et al., 2007; ROSA NETO, 2002).

A criança é um ser dinâmico, complexo, em constante transformação, que apresenta uma sequência regular de crescimento físico e de desenvolvimento neuropsicomotor. Esse desenvolvimento sofre a influência contínua de fatores intrínsecos e extrínsecos que provocam variações de um indivíduo para outro e que tornam único o curso do desenvolvimento de cada criança. Os fatores intrínsecos determinam as características físicas da criança, a cor dos seus olhos e outros atributos geneticamente determinados. Os fatores extrínsecos começam a atuar desde a concepção, estando diretamente relacionados com o ambiente da vida intrauterina, proporcionado pela mãe por meio das suas condiçôes de saúde e nutrição. Após o nascimento, o ambiente em que a criança vive, os cuidados que lhe são dispensados pelos pais, o carinho, estímulos e alimentação passam a fazer parte significativa no processo de maturação que a leva da dependência à independência. Do ponto de vista clínico, qualquer evento ambiental nocivo que ocorra na vida fetal, durante o parto e nos primeiros anos de vida, pode lesar o Sistema Nervoso Central (SNC) (BRASIL, 2002).

Em cada idade, o movimento toma características significativas e a aquisição ou aparição de determinados comportamentos motores tem repercussóes importantes no desenvolvimento da criança. Cada aquisição influencia na anterior, tanto no domínio mental como no motor, através da experiência e troca com o meio (ANDRADE; LUFT; ROLIM, 2004; FONSECA, 1988).

Segundo Andrade, Luft e Rolim (2004), todo comportamento envolve processos neurais específicos, que ocorrem desde a percepção do estímulo até a efetivação da resposta selecionada. Esses processos neurais possibilitam o comportamento e o aprendizado, que acontecem de maneiras diferentes no cérebro. Desde que nascemos, a maturação do sistema nervoso possibilita o aprendizado progressivo de habilidades. À medida que uma determinada área cerebral amadurece, a pessoa exibe comportamentos correspondentes àquela área madura, desde que tal função seja estimulada.

As crianças da primeira infância, ou seja, de 2 a 6 anos, apresentam as habilidades percepto-motoras em pleno desenvolvimento, mas ainda confundem direção, esquema corporal, temporal e espacial. As váriashabilidades fundamentais estão se desenvolvendo, de forma que movimentos bilaterais, como pular, náo apresentam tanta consistência nas atividades unilaterais. $\mathrm{O}$ controle motor refinado ainda não está totalmente estabelecido, embora esteja se desenvolvendo rapidamente, os olhos ainda não estão aptos a períodos extensos de trabalhos minuciosos.

Assim, o desenvolvimento psicomotor envolve o desenvolvimento funcional de todo corpo e suas partes. Ao nascer, a atividade na criança começa por ser elementar, descontínua, esporádica, difusa, grosseira e indiferenciada. Dessa forma, o comportamento psicomotor primeiro é de ordem motora (reflexa ou voluntária) para posteriormente ser de ordem mental (NICOLA, 2004).

Um desenvolvimento psicomotor adequado apresenta gradativamente uma tipologia e qualidade dos movimentos, que se integram numa certa ordem, sendo caracterizado pela precisão (dos 0 aos 7 anos), pela rapidez (dos 7 aos 10 anos) e pela força muscular 
(dos 10 aos 15 anos). Alcança seu ápice definitivo aproximadamente aos 15 anos (HAYWOOD; GETCHELL, 2004). Na evolução psicomotora da criança ocorrem dois processos que se complementam e se inter-relacionam, a diferenciação e a integração. Esses processos acontecem de forma recíproca e simultânea, resultando em aumento de força, de rapidez, de precisão e facilidade de movimento. Assim, a agitação e a imperícia motora dos primeiros meses são substituídas por uma sucessiva precisão e aperfeiçoamento do controle mental sobre o comportamento motor como consequência da organização da corticalização e consequente processo de mielinização (NICOLA, 2004).

À medida que ocorre o contato da criança com o meio, a motricidade estabelece cada vez mais dependência recíproca com a consciência, sendo que o progresso das estruturas motoras e neuro-perceptivas influi no grau de maturidade intelectual. Conforme a criança adquire comportamentos motores ocorre uma movimentação ativa e intencional, na mesma medida a criança vai conhecendo as suas possibilidades físicas, sensoriais e mentais (OLIVEIRA, 2002).

$\mathrm{O}$ desenvolvimento motor constitui-se por um processo de aquisiçôes de habilidades que modificam o comportamento motor de um sujeito (GABBARD; RODRIGUES, 2010), sendo que esse pode ser classificado em dois grandes grupos: comportamento motor grosso ou global e comportamento motor fino ou adaptativo (PESSOA, 2003). O comportamento motor grosso ou global, ou também denominado de coordenação motora global, refere-se à atividade dos grandes músculos, responsáveis pela manutenção postural e pelos movimentos globais (OLIVEIRA, 2002). O desenvolvimento das habilidades motoras globais possui uma grande variabilidade e depende tanto da maturação neurológica como das oportunidades de exploração e interação no ambiente onde estão inseridos (THELEN, 1995).

A criança passa grande parte de sua vida na escola e por isso sua conduta está representada pela sua atividade motora. As crianças correm imitando os caminhôes, carros, animais e põem-se a correr e rapidamente saltar de diferentes formas, como galopar, subir em árvores, dentre outras, e tudo isso é relaxamento corporal, o bem-estar da liberação física. A perfeição progressiva do ato motor implica um funcionamento global dos mecanismos reguladores do equilíbrio e da atitude. Quando a criança está capacitada para isso, certas condiçôes de execuçấo permitem reforçar os atos de ação (vivacidade, força muscular, resistência etc.). Mas é através da brincadeira espontânea que a criança descobre os ajustes diversos, complexos e progressivos da atividade motriz, resultando em um conjunto de movimentos coordenados em funçấo de um objetivo a ser alcançado (ROSA NETO, 2002).

A coordenação motora global depende da capacidade de equilíbrio, do ajustamento postural do indivíduo, da integraçáo entre sistema nervoso central e tônus muscular efetivo que se adapte rapidamente às alteraçóes, da força muscular e flexibilidade articular, da dissociação dos movimentos (OLIVEIRA, 2002; BLY, 1994).

O equilíbrio é a base primordial de toda ação diferenciada dos segmentos corporais, é o estado de um corpo quando forças distintas que atuam sobre ele se compensam e anulam-se mutuamente. O que caracteriza o equilíbrio tônico postural é o mecanismo complexo dos reflexos de equilíbrio, derivado, por sua vez, de um conjunto de informaçóes proprioceptivas. Tal conjunto é constituído de redes de informação sensorial. Esse jogo complexo é o que se traduz nas oscilaçôes e nas flutuações que constituem a realidade do equilíbrio na posição ortostática (ROSA NETO, 2002).

O córtex pré-central corresponde a motricidade fina e tem um papel fundamental no controle dos movimentos isolados das máos e dos dedos para pegar o alimento. A importância das áreas córtico-sensomotoras das mãos e dos dedos faz ressaltar a fineza extrema dos controles táteis e motores (ROSA NETO, 2002).

A coordenação motora fina, também denominada de comportamento motor adaptativo, é responsável pelos movimentos e pela destreza manual (como escrever, desenhar, costurar etc.), sendo representada pelos pequenos músculos envolvidos na coordenação óculo-manual (PESSOA, 2003). Dessa forma, a motricidade fina constitui o conjunto de movimentos de certos segmentos do corpo ou a capacidade de controlá-los, com emprego de força mínima, a fim de atingir uma resposta precisa à tarefa (ROSA NETO, 2002).

A coordenação visuo-manual inclui a fase de transporte da máo, seguida da fase de agarre e manipulação, resultando em uma ação conjunta entre objeto/olho/mão. A atividade manual, guiada por meio da visão, utiliza-se também do conjunto dos músculos que asseguram a manutenção dos ombros, dos braços e do antebraço (OLIVEIRA, 2002).

$\mathrm{O}$ desempenho nas atividades que envolvam a coordenação entre objeto/olho/mão depende do nível de aprendizado e da evolução do desenvolvimento motor. A motricidade fina é aperfeiçoada entre os 6 e 7 anos de idade, sendo de grande importância para o contexto escolar, exigindo além de gestos 
minuciosos, a habilidade de concentração do aluno (FONSECA; BELTRAME; TKAC, 2008; ROSA NETO, 2002; FONSECA, 1995).

Segundo Souza e Marino (2013) e Grigolatto et al. (2008), a Terapia Ocupacional tem por objetivo promover o desempenho ocupacional da criança, favorecendo o desenvolvimento das habilidades adequadas para cada faixa etária.

A Terapia Ocupacional é definida pela World Federation Occupational Therapists (WORLD..., 2014) como uma profissão centrada no cliente e na promoção da saúde e bem-estar por meio da ocupação. $\mathrm{O}$ principal objetivo do terapeuta ocupacional constitui melhorar a capacidade de pessoas para a realização de atividades que querem, precisam ou se espera que façam, modificando a ocupação ou o ambiente para favorecer o desempenho ocupacional.

Nesse sentido, Trombly e Radomski (2005) afirmam que o terapeuta ocupacional pode combinar as habilidades do paciente com as atividades que serão realizadas ou deseja realizar, selecionando, dessa forma, a atividade mais apropriada para a correção do problema entre as disponíveis e as que interessam ao paciente.

Considera-se que avaliações e estimulações específicas para cada área do desenvolvimento são de extrema importância, pois somente por meio dessas obtêm-se dados concretos sobre qual área está deficitária e necessita ser estimulada. $\mathrm{O}$ presente estudo teve por objetivo elaborar um plano de intervenção dirigida e avaliar seu impacto em uma criança com atraso no desenvolvimento da coordenaçáo motora global, motora fina e equilíbrio. Mediante os resultados obtidos, torna-se possível contribuir com o delineamento do trabalho da Terapia Ocupacional junto a crianças com atraso no desenvolvimento no equilíbrio, na coordenaçáo motora fina e global.

\section{Metodologia}

\subsection{Método}

A presente pesquisa utilizou o design metodológico de estudo quase experimental do tipo pré e pós-teste, também denominado ensaio ou experimento não aleatório. Esse tipo de design se caracteriza pela intervenção do investigador nas características que estão sendo investigadas, sendo que não há alocação aleatória dos participantes aos grupos que receberam a intervenção. Os grupos que receberam a intervenção foram formados considerando os critérios operacionais do estudo para composição da amostra e recrutamento de voluntários (SHADISH, 2001; KENNY, 1975).

\subsection{Participante e local}

A participante da pesquisa foi uma criança do sexo feminino de 4 anos de idade com histórico de traumatismo crânio encefálico (TCE), meningite, hidrocefalia (sendo necessário fazer uso de válvula) e que sofreu possível agressão física quando bebê. A criança realiza atendimento com Fonoaudiologia e Terapia Ocupacional uma vez por semana em uma instituição de reabilitação infantil, em uma cidade de médio porte no interior do estado de São Paulo na qual reside. A terapeuta ocupacional responsável pelos atendimentos da criança é a mesma investigadora do estudo.

Os critérios de inclusão para a seleção da participante foram: apresentar atraso no desenvolvimento da coordenação motora fina, da coordenação motora global e do equilíbrio com classificação em nível inferior para a idade cronológica segundo a Escala de Desenvolvimento Motor (EMD), e que possua idade cronológica entre 3 e 5 anos. O critério para a exclusão do participante foi a criança apresentar uma deficiência física e/ou sensorial.

\subsection{Procedimento para coleta de dados}

Esta pesquisa teve início mediante a aprovação do comitê de ética e garantiu-se durante toda a sua aplicação o cumprimento das exigências cabíveis.

Posteriormente a aprovação, ocorreu contato com a direção da instituição a fim de apresentar os objetivos da pesquisa e solicitar autorização para a realização da mesma.

A partir da concordância pela instituição foi realizado contato com a família da participante a fim de apresentar os objetivos da pesquisa, solicitar a participação e a assinatura do Termo de Consentimento Livre e Esclarecido.

\subsection{Instrumentos para coleta de dados}

O instrumento utilizado para a coleta de dados foi a Escala de Desenvolvimento Motora (EDM) de Rosa Neto (2002). Nessa bateria de testes avalia-se as aquisiçóes esperadas para cada faixa etária gerando-se um diagnóstico do crescimento, do desenvolvimento e da forma de aprendizagem da criança através de um conjunto de provas diversificadas e com dificuldade graduada. Essa bateria foi escolhida pois torna possível 
identificar atrasos no desenvolvimento, traçar o perfil motor do indivíduo e com isso verificar se sua idade motora corresponde a sua idade cronológica (ROSA NETO, 2002).

Os itens avaliados na presente pesquisa serão motricidade fina, motricidade global e equilíbrio.

\subsection{Procedimento para análise de dados}

A Escala de Desenvolvimento Motora de Rosa Neto (2002) possui um procedimento aritmético para pontuar os resultados dos testes individuais.

Como forma de realizar uma análise comparativa entre escores pré e pós-intervençáo, com o objetivo de verificar se as diferenças entre eles representam mudanças confiáveis e se são clinicamente relevantes, foram adotadas as concepçóes e os critérios formulados pelo Método JT (JACOBSON; TRUAX, 1991).

De acordo com Jacobson e Truax (1991), os testes de significância puramente estatísticos são limitados para a avaliação da eficácia de um tratamento. Os autores apontam que esses testes não fornecem informaçóes sobre a variabilidade da resposta ao tratamento dentro da amostra pesquisada, ou seja, produzem uma estimativa numérica de quantos indivíduos reagiram a um tratamento, mas não referem à forma como cada indivíduo em particular reagiu. Nesse sentido, apontam também que há uma diferença entre um efeito de tratamento no sentido estatístico e o efeito de tratamento com um significado clínico. Dessa forma, preveem a análise de significância clínica e de mudança confiável para grupos (independente do número de participantes) e/ou com sujeitos únicos submetidos a uma intervenção terapêutica, aplicáveis a uma grande variedade de problemas clínicos (WISE, 2011; JACOBSON et al., 1999; JACOBSON; FOLLETTE; REVENSTORF, 1984; 1986).

Wise (2004) em revisão realizada sobre os métodos de significância clínica e mudanças confiáveis, aponta que diversos autores recomendam a utilização do método de Jacobson-Truax, entre eles cita Speer e Greenbaum (1995), Speer (1999), Maassen (2001), McGlinchey, Atkins e Jacobson (2002) e Bauer, Lambert e Nielsen (2003). Tal consenso entre os autores se deve à possibilidade de utilização de forma generalizada do método abrangendo uma variedade de clientes, relativa facilidade de cálculo e pouca literatura que notifica necessidade de alteraçôes no método (WISE, 2004).

Esse método implica na realizaçáo de dois processos complementares, o cálculo do Índice de Mudança
Confiável (IMC) e de Significância Clínica (SC). O IMC serve para determinar se as mudanças pré e pós-intervenção podem ser atribuídas à intervenção ou se devem a erros de medida. Atua como um indicador de erro da medida obtida na avaliaçáo do cliente que irá ser comparado a uma distribuição teórica de erros de medida do instrumento. Para isso, os autores desenvolveram uma fórmula específica baseada na diferença entre pré e pós-teste dividida pelo erro padráo da diferença. A SC permite verificar se as mudanças atingidas ocorreram em uma extensão que as caracterize como clinicamente relevantes. Para analisar se a mudança pode ser considerada clinicamente significativa o método determina três critérios baseados na disponibilidade ou não de dados normativos a respeito da distribuição dos escores sobre um determinado aspecto do funcionamento avaliado (JACOBSON; TRUAX, 1991).

Ao aplicar essa métrica na amostra dos participantes de um programa de intervenção, pode-se determinar a porcentagem de indivíduos que melhoraram com a intervenção mas não se recuperaram, o percentual de indivíduos que se recuperaram e o percentual de indivíduos que permaneceram inalterados ou que pioraram durante o tratamento. Esses percentuais descritivos podem ser comparados entre os grupos por meio de análises de tabelas de contingência para determinar se as diferenças observadas entre os grupos são estatisticamente significativas ou podem simplesmente ser usadas de forma descritiva para aumentar o padrão das comparaçóes entre grupos baseadas em diferenças. De qualquer forma, as proporções fornecem informações valiosas sobre a variabilidade do resultado dentro de cada condiçấo de tratamento e por isso determinam a importância prática da intervenção (VILLA; AGUIAR; DEL PRETTE, 2012; DEL PRETTE; DEL PRETTE, 2008; 2012; JACOBSON et al., 1999).

\subsection{Plano de intervenção}

As atividades realizadas durante o período de intervenção foram dirigidas, específicas, intercalando a estimulação da área motora fina, global e equilíbrio. As atividades utilizadas são citadas a seguir sendo elas pontuadas na ordem de sua aplicação. A intervenção foi realizada uma vez por semana em um período de 2 meses, totalizando 10 encontros.

- Pulando em bambolês: Circuito de bombolês no qual a criança pulou ora com os dois pés juntos, ora com um pé de cada vez, dependendo do que a avaliadora solicitou. 
- Colar de canudos: Foi utilizado barbante e canudos com espessura média para criar o colar, no qual primeiramente cortamos os canudos em pedaços menores e por fim passamos o barbante por dentro dos canudos.

- Desenho vazado: São desenhos feitos em madeirite com o seu contorno em furinhos, no qual a criança tinha que passar o cadarço que faz parte do desenho pelos furos e então através do contorno formar a figura.

- Sequência de saltos no jump: A criança saltou de diversas maneiras no jump (minicama elástica), podendo ser com ambos os pés, com um pé de cada vez, para frente, para trás ou para os lados, como preferiu, tentando realizar no mínimo uma sequência de cinco saltos consecutivos, que era o solicitado pela avaliadora.

- Pulseira com canudos finos: Foi confeccionada uma pulseira com linha de bordado e canudos com espessura fina para dificultar um pouco o treino.

- Pular "cobrinha": A avaliadora, com auxílio de uma outra pessoa, fez movimentos ondulatórios no chão (cobrinha), onde a criança tinha que pular de um lado para o outro sem pisar na corda e/ou cair sentada no chão.

- Pulseira com miçangas: Foi confeccionada pulseira com fio de náilon e miçangas médias.

- Brincadeira da estátua: Foi colocado música ao fundo e entáo a criança e a avaliadora permaneceram dançando até a música parar e a avaliadora dizer "estátua" e então a criança tinha que parar na posição igual a realizada pela avaliadora.

- Costurando roupas da boneca: Utilizamos uma agulha de ponta grossa e linha de costura, o objetivo é conseguir passar a linha na agulha para em seguida costurar a roupa da boneca.

\section{Resultados}

Com a aplicação da Escala de Desenvolvimento Motor (EDM) foi avaliado o estágio de desenvolvimento psicomotor das aquisiçóes motricidade fina, global e equilíbrio.

Com o objetivo de verificar se ocorreram diferenças entre as avaliaçôes pré e pós-teste e se essas representam mudanças confiáveis e clinicamente significativas, foi utilizado o Método JT (JACOBSON; TRUAX, 1991). A análise de cada uma das aquisiçóes seguindo as normas do Método JT produziu um gráfico de dispersão.

Importante ressaltar que o Método JT produz gráficos de dispersão, sendo que a linha horizontal que constitui o gráfico representa a pré-intervençáo, também denominada de "eixo x" ou abscissa. A linha vertical do gráfico representa a pós-intervenção, sendo também denominada de "eixo y" ou ordenada. Os resultados adquiridos na pré e na pós-intervenção sáo distribuídos pelo gráfico seguindo as linhas diagonais, as linhas horizontais e as linhas verticais.

Para uma interpretação mais adequada do gráfico para o Índice de Mudança Confiável (IMC) deve-se analisar a linha diagonal central, chamada de bissetriz. Essa linha indica que quando o ponto que representa o escore do sujeito está acima dela é porque houve melhora devido a intervenção realizada e se os pontos estão abaixo dela é porque ocorreu uma piora devido à intervenção. Para os pontos localizados em cima da linha ou dentro do intervalo de confiança não podemos fazer afirmaçóes de melhora ou piora devidas à intervenção. As linhas diagonais acima e abaixo da bissetriz delimitam uma faixa de incerteza ao redor da bissetriz. Nada podemos afirmar sobre pontos localizados nessa faixa, já que indicam alteraçôes mínimas que podem ser devidas a erros de medida.

Para a melhor interpretação do gráfico para a Significância Clínica (SC) deve-se analisar as linhas horizontais e verticais. A linha horizontal central indica o Ponto de Corte para a Significância Clínica, ou seja, se o ponto que representa o escore do sujeito estiver acima dessa linha significa que o indivíduo passou para a população funcional em relação ao fator que está sendo medido. Se estiver abaixo dessa linha significa que não houve mudança no status clínico. Já a linha horizontal acima e abaixo delimitam uma faixa de incerteza acima e abaixo do Ponto de Corte para a Significância Clínica dentro da qual podem existir erros de medida, sendo assim, são confiáveis os escores que encontram-se fora dessa faixa de incerteza.

A linha vertical central separa os escores iniciais mais altos de escores iniciais baixos, ou seja, se o ponto que representa o escore do sujeito estiver à direita dessa linha, ele já estava na população funcional (antes mesmo da intervenção). Se o ponto que representa o escore do sujeito estiver à esquerda dessa linha, já fazia parte da população disfuncional antes da intervenção. Já os traçados verticais à direita e à esquerda delimitam uma faixa de incerteza à direita è̀ esquerda da linha vertical dentro da qual podem existir erros de medida. 
A seguir, na Figura 1 ilustra-se o formato e constituição do gráfico, informando-se o significado de cada um dos quadrantes que são constituídos pela junção das linhas horizontais, verticais e diagonais.

Dessa forma, a apresentação dos resultados segue a ordem: avaliação pré-teste e pós-teste 1 dos itens motricidade fina, motricidade global e equilíbrio.

Em relação à motricidade fina, o resultado da análise entre a avaliação pré-teste e pós-teste 1 indica que a criança (S1) obteve mudança confiável, ou seja, que esta está relacionada com a intervençáo e náo se deve a um erro de medida.

Em relação à significância clínica, ou seja, se houve mudança de status clínico, tem-se que a criança se apresentava na pré-intervenção na população disfuncional e no pós-teste 1 permaneceu nessa população. A seguir, na Figura 2, essas informações são apresentadas.

Em relação à motricidade global, o resultado da análise entre a avaliaçấo pré-teste e pós-teste 1 indica que a criança (S1) obteve mudança confiável, ou seja, que esta está relacionada com a intervençáo e não se deve a um erro de medida.

Em relação à significância clínica, ou seja, se houve mudança de status clínico, têm-se que a criança obteve alteraçôes, mas por se encontrar na faixa de incerteza (ao redor da bissetriz) não é possível afirmar nada sobre essas pois pode ser devidas a erros de medida. A Figura 3 apresenta esses dados.
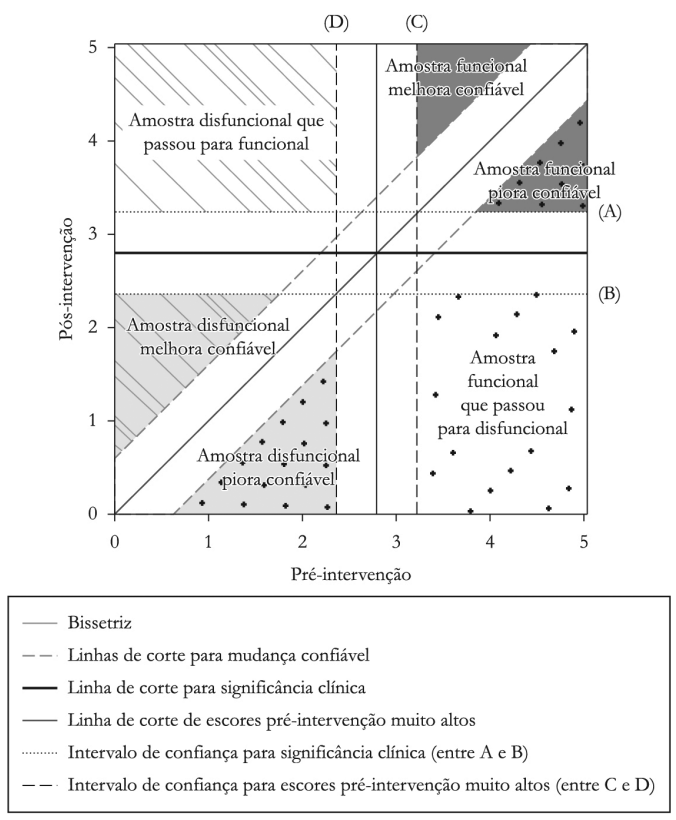

Figura 1. Modelo explicativo para o gráfico produzido pela análise segundo o Método JT (VILLA; AGUIAR; DEL PRETTE, 2012).
Em relação ao equilíbrio, o resultado da análise entre a avaliação pré-teste e pós-teste 1 indica que a criança (S1) obteve mudança confiável, ou seja, que esta está relacionada com a intervenção e não se deve a um erro de medida.

Em relação à significância clínica, ou seja, se houve mudança de status clínico, têm-se que a criança se apresentava na pré-intervenção na população disfuncional e no pós-teste 1 permaneceu nessa população. A seguir, a Figura 4 ilustra esses resultados.

Um adendo que pode ser realizado aos resultados obtidos através de observação é que nos primeiros atendimentos a criança apresentou grande dificuldade

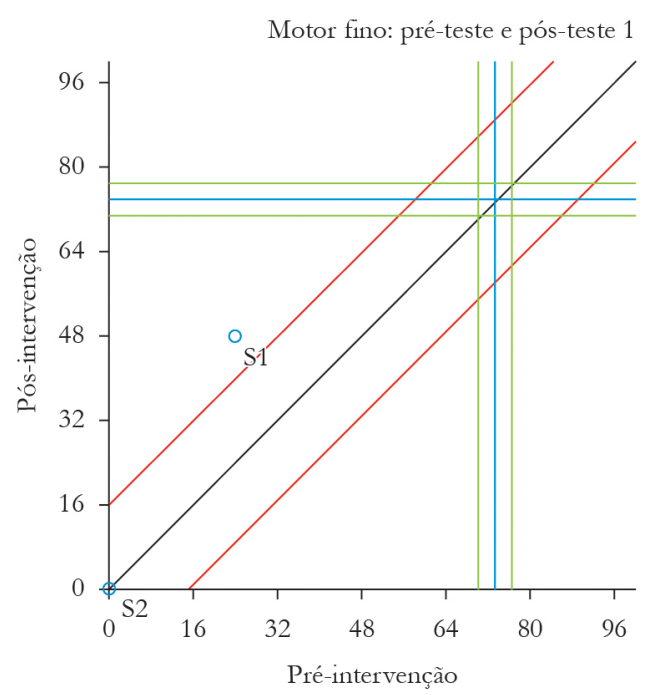

Figura 2. Motor fino: pré-teste e pós-teste 1 (gráfico 1).

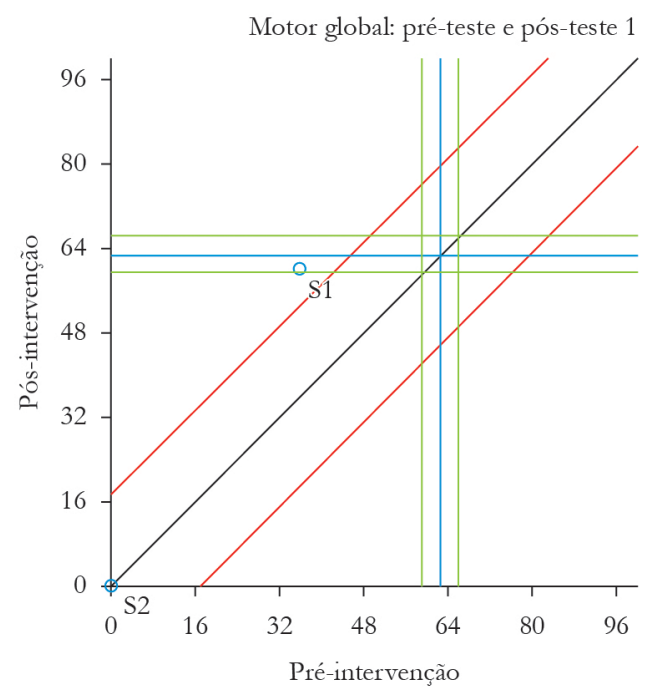

Figura 3. Motor global: pré-teste e pós-teste 1 (gráfico 2). 


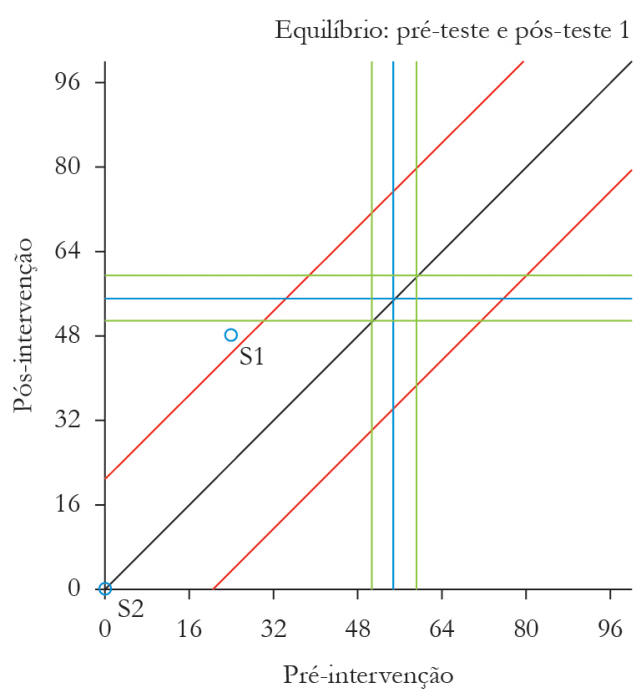

Figura 4. Equilíbrio: pré-teste e pós-teste 1 (gráfico 3).

para realizar as atividades devido ao baixo tempo de atenção, dificuldade em manter-se por muito tempo em uma mesma atividade e dificuldade de compreensão, acabando por desistir facilmente das atividades e apresentando resistência para retornar. Com isso, foi necessário o estímulo da pesquisadora através de diferentes meios e do reforço positivo para que a criança conseguisse manter-se na atividade programada tempo necessário para finalizar sua execução.

Nos últimos atendimentos foi possível notar uma significativa melhora na atenção e concentração da criança durante as atividades, promovendo melhor rendimento e diminuindo o nível de dependência da criança em relaçáo aos estímulos apresentados pela avaliadora para que realizasse as atividades.

\section{Discussão}

O atraso nos aspectos psicomotores, coordenação motora fina, global e equilíbrio apresentado pela participante deste estudo vai ao encontro com atrasos já detectados em outros estudos que avaliaram o desenvolvimento psicomotor de crianças (FIGUEIREDO; EMMEL; ROSÁRIO, 2013; AMARO et al., 2009; PELLEGRINI et al., 2005; BERESFORD; QUEIROZ; NOGUEIRA, 2002).

Os resultados obtidos no presente estudo demonstram que ocorreram mudanças positivas confiáveis nos itens psicomotores que passaram por estimulaçáo. Com isso, infere-se que a intervenção proposta teve um efeito positivo sobre o desenvolvimento da criança, através do plano de tratamento elaborado para cada item, pois no início da intervenção a criança apresentava-se em níveis abaixo de sua faixa etária nos três itens psicomotores avaliados no presente estudo e após a intervenção pôde-se observar que a criança conseguiu se adequar ao equiparado para sua faixa etária.

Essas mudanças confiáveis nas áreas estimuladas corroboram com pesquisas que apontam para os benefícios de intervençôes nos atrasos no desenvolvimento motor e da coordenação motora (NOBRE, 2012; SILVA et al., 2011; BRAGA et al., 2009; MULLER, 2008; WILLRICH et al., 2008).

Na pesquisa realizada por Nobre (2012), a maioria das crianças submetidas a atividades elaboradas dentro de um programa de intervenção motora apresentaram melhor desempenho em atividades locomotoras e de controle de objeto em relaçáo às crianças que não foram submetidas a um programa de intervenção.

Silva et al. (2011), em seu estudo, afirmaram diferenças estatisticamente significativas após a intervenção motora, demonstrando que essa foi efetiva para a melhora do desempenho/habilidade motora dos escolares com indicativo de transtorno do desenvolvimento da coordenação (TDC).

No estudo realizado por Braga et al. (2009) verificaram-se pesquisas, tanto nacionais quanto internacionais, relacionadas a intervenção, sendo que os resultados encontrados demonstram que após o período de estimulaçáo do programa interventivo, os participantes apresentaram melhora significativa no desempenho motor.

Muller (2008) obteve diferenças estatisticamente significativas no programa motor concretizado, reforçando com isso a relevância do desenvolvimento de intervençóes motoras para crianças com atrasos motores e salientando que quanto mais precoce for diagnosticado o atraso motor, mais cedo se elaboram propostas interventivas a fim de potencializar o desenvolvimento.

O estudo de Willrich et al. (2008) mostra os efeitos de programas de intervençáo motora no desenvolvimento motor em crianças desde os primeiros anos de vida. Os resultados demonstram que as intervençóes nos primeiros anos de vida podem auxiliar nos ganhos do desenvolvimento humano e prevenir as incapacidades ou condiçóes indesejáveis em crianças com atraso no desenvolvimento.

Na presente pesquisa foi constatada uma mudança confiável quanto ao desenvolvimento da coordenação motora fina, o que significa que a criança apresentou "evolução" na área devido a estimulação realizada no período de tratamento. Os resultados encontrados coincidem com a pesquisa realizada por Poeta e 
Neto, que referem que o programa de estimulação, baseado em atividades reeducativas realizadas de forma lúdica possibilitou mudanças positivas na motricidade fina (POETA; ROSA NETO, 2005). No estudo de Santos et al. (2009) foi confirmada a relevância da estimulaçáo psicomotora em uma criança com TDAH para o desenvolvimento da coordenação motora fina, constatando-se mudança de perfil psicomotor de eupráxico para hiperpráxico.

Em relação à motricidade global, o resultado da análise indica que a criança obteve mudança confiável, ou seja, que esta está relacionada com a intervenção e não se deve a um erro de medida. Valentini (2002) afirma que crianças que foram introduzidas a uma grande variedade de estratégias apropriadas e divertidas obtiveram melhorias motoras e atitudes positivas em relação às atividades de movimento no futuro, resultando em melhorias nas habilidades de locomoção e de controle de objeto.

Sacon et al. (2009) afirmam que a estimulação da coordenaçấo motora global e motricidade em um grupo de crianças é fundamental para que elas possam se movimentar sem nenhum impedimento e manter essas habilidades íntegras, além de aperfeiçoá-las para a facilitação do seu desempenho motor, e que a criação de programas de estimulação, tanto com atendimento ambulatorial em instituiçóes especializadas quanto no atendimento educacional, seja em escolas de educação infantil, clínicas ou unidades hospitalares, oportuniza e qualifica a própria criança a se relacionar totalmente com o contexto social, além de potencializar o seu desempenho neuropsicomotor.

O movimento motor global é um movimento sinestésico, tátil, labiríntico, visual, espacial, temporal e assim por diante, sendo esses movimentos dinâmicos corporais de grande importância para a melhora dos comandos nervosos e para afinamento das sensações e percepções. O que é educativo na atividade motora não é a quantidade de trabalho efetuado nem o registro alcançado, mas sim o controle de si mesmo obtido pela quantidade de movimento executado, isso é, a precisão e maestria de sua execução (ROSA NETO, 2002).

A área relacionada ao equilíbrio também obteve mudança confiável no status clínico, o que reforça a importância da realização de estimulaçóes para o desenvolvimento motor na infância. Esse fator evolutivo pode ser constatado também no estudo realizado por Campos et al. (2008), no qual identificou-se o perfil motor de crianças com baixo nível social e verificou-se o efeito de um programa de intervenção psicomotora. Tal estudo obteve como resultado um aumento estatístico significativo na pontuação das áreas de tonicidade, equilibração, estrutura espaço-temporal, praxia global e fina nas crianças avaliadas, o que vem a confirmar a importância de programas de intervenção para o desempenho psicomotor. Santos et al. (2007) referem o estudo de Lefèvre e Penna, no qual, a partir de uma estimulação realizada, ocorreu um aperfeiçoamento das habilidades das crianças e conforme a sua repetição notou-se a melhora do índice de sucesso e, consequentemente, o refinamento da movimentaçáo e do equilíbrio.

Os resultados apresentados por este estudo, possibilitam o reconhecimento da açáo da Terapia Ocupacional enquanto uma das profissóes que compóem a equipe multidisciplinar voltada à intervenção precoce junto a crianças com atrasos no desenvolvimento da coordenação motora fina, global e equilíbrio. Dessa forma, o terapeuta ocupacional possui funçôes específicas, como as realizadas nesta pesquisa, por exemplo, a aplicação de instrumentos de avaliação específicos e a elaboração de um programa de atendimento/estimulação que atenda às reais necessidades da criança.

Segundo Perin (2010), a Terapia Ocupacional propóe açóes que favorecem o desenvolvimento global da criança e parte do princípio de que nada se aprende sem o pegar, manipular, sentir, construir, diferenciar. O processo de Terapia Ocupacional inclui atividades terapêuticas lúdicas através das estimulaçốes e constitui um processo interacionista que ajuda a efetivar a aprendizagem e a superar dificuldades, tanto nos movimentos globais como específicos.

O terapeuta ocupacional pode também auxiliar pais, professores e a própria criança a desenvolverem uma melhor compreensão das dificuldades de coordenação que a criança está enfrentando. Dessa forma, atua no ensino de estratégias para compensar os problemas motores apresentados e oferece à criança oportunidades adequadas para conscientização de seus pontos fortes e de suas limitaçóes para praticar e aprender habilidades motoras e para que possa lidar com suas dificuldades. Assim, a Terapia Ocupacional tem uma importante atuaçáo junto às crianças com transtornos motores e seus familiares, uma vez que cria estratégias de estimulaçáo como a integraçáo sensorial, reorganiza o cotidiano, realiza o treino de habilidades para a vida diária, fornece adaptação de materiais, avaliação do ambiente e indicação de modificaçóes de acordo com as necessidades de cada criança (MAZER; DELLA BARBA, 2010).

Tavares et al. (2008) refere que a intervençáo precoce é uma ação efetiva que visa proporcionar estímulos, facilitar aquisiçóes ou prevenir disfunçóes aproveitando o grande potencial de maturidade 
neurológica devida a plasticidade neural, que ocorre desde as primeiras etapas do desenvolvimento neuropsicomotor.

A estimulação precoce é definida como uma medida de apoio integrado, centrado na criança e na família, mediante açôes de natureza preventiva e habilitativa, designadamente no âmbito da educaçáo, saúde e açáo social, com vista a: a) assegurar condiçôes facilitadoras do desenvolvimento da criança com deficiência ou em risco de atraso grave de desenvolvimento, b) potenciar a melhoria das interaçôes familiares e c) reforçar as competências familiares como suporte da sua progressiva capacitação e autonomia face à problemática da deficiência (PORTUGAL, 1999).

Nesse sentido, a Terapia Ocupacional realiza a avaliação e a concretização da intervenção o mais precoce possível, de acordo com as necessidades e capacidades individuais de cada criança, visando estimular e integrar as várias áreas e aquisiçōes motoras para obter melhor desenvolvimento psicomotor e qualidade de vida.

\section{Considerações finais}

Neste estudo avaliou-se o impacto de uma intervenção junto a uma criança com atraso no desenvolvimento psicomotor. Os resultados demonstraram mudanças positivas confiáveis nos itens coordenação motora fina, global e equilíbrio.

Dessa forma, os resultados confirmam um efeito positivo do programa de intervenção proposto, tendo as atividades elaboradas e realizadas com a participante do estudo favorecido o aprimoramento desses itens. Além disso, o presente estudo reforça a relevância de programas de estimulaçáo para o desenvolvimento das habilidades psicomotoras de crianças com atrasos no desenvolvimento.

A relevância da atuação de terapeutas ocupacionais na intervenção com crianças com atraso no desenvolvimento da coordenaçáo motora fina, global e equilíbrio também ficou demonstrada com os resultados obtidos. Esse profissional atende às necessidades de intervenção com essas crianças, na medida em que são habilitados nas avaliaçôes e elaboração de programas de intervenção que vão ao encontro da necessidade de aprimoramento dos componentes de desempenho motor. Nesse sentido, o terapeuta ocupacional compóe a gama de profissionais específicos que são necessários ao atendimento precoce de crianças com atraso no desenvolvimento psicomotor.

O estudo, por envolver uma única criança, apresenta limitaçôes e os resultados devem ser considerados sob essas perspectivas. Com isso, sugere-se a continuidade de investigaçóes sobre essa temática, na medida em que determinados comportamentos motores têm repercussôes importantes no desenvolvimento da criança e que a precocidade do diagnóstico e intervenção nos atrasos influenciarão no desempenho da criança em diferentes atividades do cotidiano e consequentemente em sua qualidade de vida. Assim, ressalta-se a importância da realização de novos estudos com maior número de partícipes sobre o assunto em questão para produçáo de novos dados e descobertas sobre o desenvolvimento psicomotor e eficácia de programas de intervenção.

\section{Referências}

AMARO, K. N. et al. Desenvolvimento motor em escolares com dificuldade de aprendizagem. Revista Digital, Buenos Aires, año 14, n. 133, p. 1-1, 2009. Disponível em: <http://www.efdeportes.com/efd133/desenvolvimento-motor-em-escolares.htm>. Acesso em: 19 mar. 2014.

ANDRADE, A.; LUFT, B. C.; ROLIM, M. K. S. B. O desenvolvimento motor, a maturação das áreas corticais e a atenção na aprendizagem motora. Revista Digital, Buenos Aires, año 10, n. 78, p. 1-1, 2004. Disponível em:< http://www.efdeportes.com/efd78/motor.htm>. Acesso em: 19 mar. 2014.

BERESFORD, H.; QUEIROZ, M.; NOGUEIRA, A. B. Avaliação das relaçóes cognitivas e motoras na aquisição instrucional das habilidades para a aprendizagem da linguagem escrita. Revista Ensaio: Avaliação Política Pública Educacional, Rio de Janeiro, v. 10, n. 37, p. 493501, 2002.

BLY, L. Motor skills acquisition in the first year: an illustrated guide to normal development. Tucson: Therapy Skill Builders, 1994.

BRAGA, R. K. et al. A influência de um programa de intervenção motora no desempenho de habilidades locomotoras de crianças com idade entre 6 e 7 anos. Revista de Educação Física/UEM, Maringá, v. 20, n. 2, p. 171181, 2009.

BRASIL. Ministério da Saúde. Secretaria de Políticas de Saúde. Departamento de Atenção Básica. Saúde da criança: acompanhamento do crescimento e desenvolvimento infantil. Brasília: Ministério da Saúde, 2002.

CAMPOS, A. C. et al. Intervenção psicomotora em crianças de nível socioeconômico baixo. Revista Fisioterapia e Pesquisa, São Paulo, v. 15, n. 2, p. 188-193, 2008. http:// dx.doi.org/10.1590/S1809-29502008000200013.

DEL PRETTE, Z. A. P.; DEL PRETTE, A. Intervençóes baseadas em evidências e método JT. In: VILLA, M. B.; AGUIAR, A. A. R.; DEL PRETTE, Z. A. P. Intervençóes baseadas em evidências: aplicaçóes do método JT. São Carlos: EDUFSCar, 2012. p. 11-25. 
DEL PRETTE, Z. A. P.; DEL PRETTE, A. Significância clínica e mudança confiável: a efetividade das intervenções em psicologia. Psicologia: Teoria e Pesquisa, Brasília, v. 24, n. 4, p. 497-506, 2008.

FIGUEIREDO, M. O.; EMMEL, M. L. G.; ROSÁRIO, P. Caracterização do desenvolvimento psicomotor de alunos com dificuldade de aprendizagem. In: CONGRESSO INTERNACIONAL GALEGO-PORTUGUÊS DE PSICOPEDAGOGIA, 12., 2013, Braga. Anais... Braga: Universidade do Minho, 2013. p. 53365350. Disponível em: <http://webs.ie.uminho.pt/xiigp/ at11.pdf>. Acesso em: 19 mar. 2014.

FONSECA, F. R.; BELTRAME, T. S.; TKAC, C. M. Relação entre o nível de desenvolvimento motor e variáveis do contexto de desenvolvimento de crianças. Revista da Educação Física/UEM, Maringa, v. 19, n. 2, p. 183194, 2008.

FONSECA, V. Da filogênese à ontogênese da motricidade. Porto Alegre: Artes Médicas, 1988.

FONSECA, V. Manual de observação psicomotora: significação psiconeurológica dos fatores psicomotores. Porto Alegre: Artes Médicas, 1995.

GABBARD, C.; RODRIGUES, L. P. Testes contemporâneos de avaliação do comportamento motor infantil. In: MOURA-RIBEIRO, M. V. L.; GONÇALVES, V. M. G. Neurologia do desenvolvimento da criança. Rio de Janeiro: Revinter, 2010. p. 270-287.

GRIGOLATTO, T. et al. Intervenção terapêutica ocupacional em CTI pediátrico: um estudo de caso. Cadernos de Terapia Ocupacional da UFSCar, São Carlos, v. 16, n. 1, p. 37-46, 2008.

HAYWOOD, K. M.; GETCHELL, N. Desenvolvimento motor ao longo da vida. Porto Alegre: Artmed, 2004.

JACOBSON, N. S. et al. Methods for defining and determining the clinical significance of treatment effects: description, application, and alternatives. Journal of Consulting and Clinical Psychology, Washington, v. 67, n. 3, p. 300-307, 1999. http://dx.doi.org/10.1037/0022-006X.67.3.300. PMid:10369050

JACOBSON, N. S.; FOLLETTE, W. C.; REVENSTORF, D. Psychotherapy outcome research: methods for reporting variability and evaluating clinical significance. Behavior Therapy, New York, v. 15, n. 4, p. 336-352, 1984. http://dx.doi.org/10.1016/S00057894(84)80002-7.

JACOBSON, N. S.; FOLLETTE, W. C.; REVENSTORF, D. Toward a standard definition of clinically significant change. Behavior Therapy, Elsevier, v. 17, p. 308-311, 1986.

JACOBSON, N. S.; TRUAX, P. Clinical significance: a statistical approach to defining meaningful change in psychotherapy research. Journal of Consulting and Clinical Psychology, Washington, v. 59, n. 1, p. 12-19, 1991. http://dx.doi.org/10.1037/0022-006X.59.1.12. PMid:2002127
KENNY, D. A. A quasi-experimental approach to assessing treatment effects in the nonequivalent control group design. Psychological Bulletin, Washington, v. 82, n. 3, p. 345-362, 1975. http://dx.doi.org/10.1037/00332909.82.3.345.

MAZER, E. P.; DELLA BARBA, P. C. S. Identificação de sinais de transtornos do desenvolvimento da coordenação em crianças de três a seis anos e possibilidades de atuação da terapia ocupacional. Revista de Terapia Ocupacional da USP, São Paulo, v. 21, n. 1, p. 74-82, 2010.

MULLER, A. B. Efeitos da Intervençâo motora em diferentes contextos no desenvolvimento da criança com atraso motor. 2008. 186 f. Dissertação (Mestrado em Movimento Humano) - Universidade Federal do Rio Grande do Sul, Rio Grande do Sul, 2008.

NICOLA, M. Psicomotricidade: manual básico. Rio de Janeiro: Revinter, 2004.

NOBRE, F. S. S. et al. Intervenção motora como fator determinante no desenvolvimento motor: estudo comparativo e quase experimental. Revista Acta Brasileira do Movimento Humano, Santa Catarina, v. 2, n. 2, p. 76-85, 2012.

OLIVEIRA, G. C. Psicomotricidade: educação e reeducação num enfoque psicopedagógico. Petrópolis: Editora Vozes, 2002.

PELLEGRINI, A. M. et al. O comportamento motor no processo de escolarização e a formação de professores de educação básica. Efy Deportes Revista Digital, Buenos Aires, ano 10, n. 81, 2005.

PERIN, A. E. Estimulação Precoce: sinais de alerta e benefícios para o desenvolvimento. Revista de Educação do Ideau, Getulio Vargas, v. 5, n. 12, p. 2-13, 2010.

PESSOA, J. H. L. Desenvolvimento da criança, uma visão pediátrica. Sinopse de Pediatria, Sáo Paulo, v. 9, n. 3, p. $72-77,2003$.

POETA, L. S.; ROSA NETO, F. Intervenção motora em uma criança com transtorno do déficit de atenção/ hiperatividade (TDAH). Lecturas Educacion Física y Deportes, Buenos Aires, v.10, n.89, p. 1-1, 2005. Disponível em <http://www.efdeportes.com/efd89/tdah.htm>. Acesso em: 22 maio 2014.

PORTUGAL. Despacho Conjunto 891/99. Orientaçóes reguladoras da interveção precoce para crianças com deficiência ou em risco de atraso grave de desenvolvimento e suas famílias. Diário da República de Portugal, Portugal, 19 out.1999. p.15.566-15.568. Disponível em: <http://anip.net/contents/uploads/2012/06/Desp.-Conj.-891_1999.pdf>. Acesso em: 19 mar. 2014.

ROSA NETO, F. et al. Desenvolvimento motor de crianças com indicadores de dificuldades na aprendizagem escolar. Revista Brasileira de Ciência e Movimento, Brasília, v. 15, n. 1, p. 45-51, 2007.

ROSA NETO, F. Manual de avaliação motora. Porto Alegre: ArtMed, 2002. 
SACON, A. B. et al. Estimulação em Grupos na Educação Infantil: propostas de atividades. Revista Contexto \& Saúde, Ijuí, v. 8, n. 16, p. 101-109, 2009

SANTOS, C. et al. Proposta de protocolo de exercicios, baseado na relação do equilíbrio e da coordenação motora com os hábitos de vida diaria de crianças de sete anos. Revista Brasileira de Ciências da Saúde, São Caetano do Sul, ano III, n. 11, p 8-15, 2007.

SANTOS, G.A. et al. Estudo da coordenação motora fina em uma criança com transtorno de déficit de atenção/hiperatividade. Movimentum - Revista Digital de Educação Física, Ipatinga, v. 4, n. 1, p. 1-7, 2009.

SHADISH, W. R. Quasi-experimental designs. In: SMELSER, N.J.; BALTES, P. B. International encyclopedia of the social \& behavioral sciences. Pergamon: Oxford, 2001. p. 12655-12659.

SILVA, E. V. A. et al. Programa de intervenção motora para escolares com indicativo de transtorno do desenvolvimento da coordenação. Revista Brasileira de Educação Especial, Marília, v. 17, n. 1, p. 137-150, 2011.

SOUZA, A. C.; MARINO, M. S. F. Atuação do Terapeuta Ocupacional com criança com atraso do desenvolvimento neuropsicomotor. Cadernos de Terapia Ocupacional da UFSCar, São Carlos, v. 21, n. 1, p. 149-153, 2013. http://dx.doi.org/10.4322/cto.2013.019.

TAVARES, A. P. S. et al. A Terapia Ocupacional favorecendo o desenvolvimento neuropsicomotor, ao intervir precocemente, em crianças com paralisia braquial obstétrica. 2008. 100 f. Trabalho de Conclusão de Curso (Graduação em Terapia Ocupacional) - Centro Universitário Católico Salesiano Auxilium, Lins, 2008.

THELEN, E. Motor development. A new synthesis. The American Psychologist, Washington, v. 50, n. 2, p. 79-95,
1995. http://dx.doi.org/10.1037/0003-066X.50.2.79. PMid:7879990

TROMBLY, C. A.; RADOMSKI, M. V. Terapia ocupacional para disfunçóes físicas. São Paulo: Santos, 2005.

VALENTINI, N. C. A influencia de uma intervenção motora no desempenho motor e na percepção de competencia de crianças com atrasos motores. Revista Paulista de Educação Física, São Paulo, v.16, n. 1, p. 61-75, 2002.

VILLA, M.B.; AGUIAR, A.A.R.; DEL PRETTE, Z.A.P. Intervençôes baseadas em evidências: aplicaçôes do método JT. São Carlos: EDUFSCar, 2012.

WILLRICH, A.; AZEVEDO, C. C. F.; FERNANDES, J. O. Desenvolvimento motor na infância: influência dos fatores de risco e programas de intervençáo. Revista de Neurociencias, São Paulo, v. 17, n. 1, p. 51-56, 2008.

WISE, E. A. Methods for analyzing psychotherapy outcomes: a review of clinical significance, reliable change, and recommendations for future directions. Journal of Personality Assessment, Burbank, v. 82, n. 1, p. 50-59, 2004. http://dx.doi.org/10.1207/ s15327752jpa8201_10. PMid:14979834

WISE, E. A. Statistical significance testing and clinical effectiveness studies. American Psychological Association, Chicago, v. 48, n. 3, p. 225-228, 2011. http://dx.doi. org/10.1037/a0022701. PMid:21875236

WORLD FEDERATION OF OCCUPATIONAL THERAPISTS - WFOT. Statement on Occupacional Therapy. Disponível em: < http://www.wfot.org/Portals/0/PDF/STATEMENT\%20ON\%20OCCUPATIONAL\%20THERAPY\%20300811.pdf >. Acesso: 22 mai. 2014.

\section{Contribuição dos Autores}

Letícia Carrillo Maronesi: responsável pela concepção do texto, organização de fontes, da coleta e análise dos resultados. Mirela de Oliveira Figueiredo: responsável pela concepção do texto, organizaçáo de fontes, das análises e discussão dos resultados. Elisandra dos Santos, Sheila Maria Mazer Gonçalves e Sara Domiciano Franco Campos: responsáveis pela revisão de todo o artigo e concepção final do texto. Todos os autores aprovaram a versão final do texto. 